\title{
Cognitive E-Tools for Diagnosing the State of Medical Knowledge in Students Enrolled for a Second Time in an Anatomy Course
}

\author{
Guadalupe Elizabeth Morales-Martinez \\ Cognitive Science Laboratory, IISUE, National Autonomous University of Mexico, Mexico \\ https:/ / orcid.org/0000-0002-4662-229X \\ Alberto Manuel Ángeles Castellanos, Víctor Hugo Ibarra Ramírez \\ and Magaly Iveth Mancera Rangel \\ School of Medicine, National Autonomous University of Mexico, Mexico \\ https://orcid.org/0000-0002-6496-9465 \\ https://orcid.org/0000-0003-4424-8158 \\ https://orcid.org/0000-0002-5219-3348
}

\begin{abstract}
This article illustrates the application of the Chronometric Constructive Cognitive Learning Evaluation Model to measure the structural, organizational, and temporal properties of the anatomical knowledge schemata acquired by 52 first-year medical students enrolled for a second time in an anatomy course. The participants took part in a mental representation experiment as a part of which they carried out a conceptual definition task involving anatomy concepts based on the Natural Semantic Networks (NSN) technique. A computational simulation was performed on the NSN data, after which the students took part in a semantic priming experiment involving a lexical decision task which required them to classify words related or unrelated to their anatomy schema as word/non-word. Findings revealed that, although students stored the anatomy information in their memory, they struggled to structure, consolidate, and retrieve this information from their memory. These findings suggest that students who did not get the passing grade in anatomy course may struggle with integrating and consolidating pertinent information. Thus, results showed that the constructive-chronometric cognitive approach is useful to measure the properties of schemes medical students developed on the anatomy topic.
\end{abstract}

Keywords: learning; cognitive assessment; cognitive science; anatomy; medicine students

\section{Introduction}

As students are frequently subjected to academic evaluations, and these experiences influence strongly their learning, so optimizing the evaluation 
instruments and processes has the potential to enhance the quality of learning (Ferris \& O'Flynn, 2015; Jimaa, 2011). However, selecting, creating, or modifying strategies used to evaluate knowledge gained by medical students is not an easy task, as there is a wide variety of ways to conduct such evaluations (Friedman \& Wyatt, 2006). Moreover, evaluation instruments can differ considerably in their characteristics according to the knowledge domain and the objective of the evaluation. Indeed, there are no right or wrong assessment strategies, and each instrument measures a specific aspect of students' ability or knowledge (ElYassin, 2015).

Measuring a single aspect of learning is insufficient to capture all the knowledge that students have stored during their medical training (Vantini \& Benini, 2008). For example, medical training involves making thoughtful use of communication skills, medical knowledge, technical aptitudes, and clinical reasoning. It also requires adaptive management of emotions as well as application of ethical and human values in daily medical practice to benefit the patients (Epstein, 2007). Measuring all these dimensions of clinical training is important to account for the level of learning and training that medical students have achieved throughout their studies.

To address the medical learning measurement problem, Miller (1990) proposed assessing four cognitive domains involved in the medical learning process: (1) knowledge necessary to carry out professional medical functions, (2) competence to use the medical knowledge acquired to conduct analyses, interpret findings, and make medical judgments, (3) ability to perform medical procedures, and (4) knowledge transfer concerned with applying the skills and performing procedures in real clinical settings. In sum, adequate evaluation of medical learning requires measurement of cognitive, psychomotor, and communication skills essential to work as a doctor upon graduation (Preston et al., 2020).

However, evaluation of the topics considered as the scientific foundation of medicine (e.g., anatomy, microbiology, pharmacology) presently focuses on testing factual knowledge through summative assessments (Samarasekera et al., 2015). This approach to medical evaluation has received extensive criticism since summative evaluation is generally informative and non-formative and typically considers only one learning level (knowledge stored in one's memory). Thus, it cannot be adopted to assess other skills and types of knowledge (e.g., ability to apply knowledge to a real setting) fundamental to the medical practice.

In addition, as the medical science is constantly evolving, the knowledge and skills medical students need to master constantly change. These conditions point to the need to innovate evaluation methods and reorient and restructure the evaluation system to be able to meet the new demands in all dimensions of medical training (Boulet \& Durning, 2019; Ferris \& O'Flynn, 2015).

These challenges can be addressed by drawing upon various ways to evaluate medical knowledge at different levels (declarative, procedural, metacognitive) rooted in cognitive psychology, by using advances in computer science technology and human mind science. In this regard, Arieli-Attali (2013) argued 
that the incorporation of technological and scientific advances into learning assessment systems is essential to more objectively evaluate learning outcomes and is better aligned with the new reality of the medical profession. The use of new technologies in the learning evaluation can also allow researchers and practitioners to comprehend the learners' cognitive mind, thereby facilitating the identification of the cognitive processes student employ to provide answers during tests.

\subsection{Cognitive Assessment of Academic Learning}

The way students learn from the cognitive perspective remains insufficiently explored (Pozo, 2006). However, cognitive studies of human memory have made it possible to establish the measurement parameters reflecting the process of incorporation or accommodation of declarative, procedural, and eidetic knowledge in the mental structures of the human brain.

From a cognitive point of view, acquisition of declarative knowledge may involve formation of new information nodes in one's memory, or the establishment of new relationships between the existing information nodes in one's knowledge structures (Bower, 1975). The process of learning may also involve adjustment of the weights assigned to the relationships between the nodes, restructuring of the knowledge schemas (Lopez et al., 2014; Rumelhart \& Norman, 1975), or adding new forms of production or procedures to the existing ones (Anderson, 1976). Hence, approaching the evaluation of academic learning from the cognitive perspective would necessitate measurement of the changes in the organization, structure, temporality, and behavior of the mental schemas that students develop as they gain relevant knowledge in class. In this regard, cognitive psychology offers theoretical and methodological tools to guide the evaluation of cognitive changes in the mental structures of knowledge due to learning over a course of an academic year.

A central assumption of the cognitive view is that human beings can store information in cognitive structures called schemas. These structures comprise of information nodes or concepts characterized by configuration, relationships, temporality, and dynamic properties. These characteristics can be measured through different cognitive tools, such as semantic networks, computational simulations, and reaction time instruments.

To illustrate the usefulness of mental representation techniques in the educational field, Morales-Martinez et al. (2018) employed Natural Semantic Networks (NSN) to observe the cognitive structure of knowledge that engineering students formed in a computational usability course. Their results revealed that the students who did not pass the course developed incomplete schemas with characteristics similar to those of schemas developed by students who encountered the subject for the first time (e.g., Urdiales-Ibarra et al., 2018). After reviewing the computational usability content again in a corrective course, these students were able to form an integrated schema of the information learned in the course.

Urdiales-Ibarra et al. (2018) applied the NSN technique to measure the effect of concept maps on the biology knowledge schemas developed by high school 
students. The visual analysis of the refined sematic networks (RSNs) revealed that students began the course with fragmented biology knowledge structures. At the end of the course, the students were able to unify their biological knowledge structures, regardless of whether they made use of conceptual maps as learning tools.

Findings yielded by extant studies in this domain suggest that RSNs can provide valuable information on the way in which students incorporate new conceptual nodes in their memory and the way in which they organize and structure them. Furthermore, when supplemented with computer simulations, this technique provides information on the cognitive tenets underlying the knowledge storage in human memory, and on the cognitive processes that participate in the formation of psychological meanings based on the information nodes they assimilate in their memory. For example, Gonzalez et al. (2018a) and Gonzalez et al. (2018b) explored the learning of moral concepts by high school students and found that, even though the students related concepts that did not have a semantic relationship (e.g., father-police), in schema terms, these concepts seemed to connect through a psychological meaning.

On the other hand, cognitive psychologists assume that schemas are dynamic and emergent structures. Gonzalez et al. (2018a) explored this property in the moral schemas of high school students through computational simulations. They observed that, when they activated the most relevant concepts of the NSN of the moral schema (TRUST, RESPECT, LOVE), no other concept of the network was co-activated. However, when they activated concepts that did not seem to have a relevant semantic value according to the RSN analysis (e.g., GOD), other concepts without a direct relationship to the activated concept (RIGHTS, TRUTH) were coactivated. These results suggest that computational simulations can provide implicit information that is retained in knowledge structures and that emerges with the activation of concepts that do not necessarily have the highest semantic weight or the highest frequency of appearance in the natural semantic NSN.

Furthermore, cognitive psychology also postulates that every cognitive process, and thus learning, is typified by time. Lopez and Theios (1992) suggested that, when a knowledge schema is acquired or modified during the human learning process, a cognitive activity is generated that can be identified by its temporary nature (temporary imprint). To explore this principle in the educational field, Lopez et al. (2014) carried out a study as a part of which psychology students were required to master Piaget's theory. Participants were presented with pairs of words that can be related (associatively or schematically) or do not present any relationship. They were instructed to read the first word in the pair before determining whether the second word is correctly or incorrectly written. The researchers reported that the schematic word recognition latencies at the end of the course were significantly lower than the latencies obtained at the beginning of the course-a phenomenon known as schematic priming (Lopez \& Theios, 1992).

The schematic priming paradigm proposes that, when students integrate information into their long-term memory related to the schematic they have 
encountered in class, the schematic word recognition latencies decrease as the course progresses. This effect has been observed in different domains, such as psychology, moral development, and engineering (e.g., Gonzales et al., 2013; Morales-Martinez et al., 2018; Morales-Martinez et al., 2020). For example, in the field of biology, Urdiales-Ibarra et al. (2018) measured the effect of concept maps on the recognition of schematic words by learners. They found that only the group that used concept maps as a learning tool exhibited schematic facilitation.

Studies based on temporal parameters, such as those noted above, can provide information on changes in the knowledge schema due to academic learning, since temporal changes in the way information is processed semantically can give clues about whether new knowledge was incorporated in students' long-term memory.

In general, application of the laws and principles of cognitive psychology, as well as the use of the tools that it offers, is useful to understand the way in which students select, store, and retrieve information in their mind. In this context, in 1989 Lopez (1989) proposed a failure rate predictor system based on the evaluation techniques derived from the theory of human information processing (PHI) and the theory of parallel information processing (PDP). This system was the basis for designing the Semantic Analyzer of Schemata or SASO-a system capable of exploring the existence of knowledge schemas in human memory (Lopez, 1996; Lopez \& Theios, 1992).

Lopez et al. (2014), Lopez et al. (2015), and Morales-Martinez et al. (2014) used the SASO model to create the Cognitive Evaluator (known by its acronym EVCOG in Spanish) which is a system that assesses academic learning. This system gave rise to the Chronometric Constructive Cognitive Learning Evaluation Model (C3LEM) (see Morales, 2020; Morales et al., 2017; Morales-Martinez et al., 2020; Morales-Martinez \& Lopez-Ramirez, 2016; Morales-Martínez et al., 2015; MoralesMartínez et al., 2016; Morales-Martinez et al., 2018; Morales-Martínez \& SantosAlcantara, 2015). In the present study, the C3-LEM was employed to assess the cognitive properties of the anatomical knowledge schemata acquired by students who did not obtain passing grade in anatomy course.

\subsection{The C3-LEM as a Cognitive Science Tool for Evaluating Medical Knowledge Acquisition}

The C3-LEM consists of the interlocking application of three types of cognitive science studies (mental representation studies, mental chronometry studies, and neuro-computational simulations) to assess organizational, structural, and dynamic aspects of the knowledge schema a learner develops. This series of studies is also known as the EVCOG procedure.

Typically, the EVCOG procedure comprises of two phases, as shown in Figure 1. First, a constructive cognitive evaluation is performed to assess students' knowledge on a certain topic. In this phase, the participants take part in an NSN study to evaluate their knowledge schema while the researcher performs neurocomputational simulations on the gathered NSN data. This if followed by the second phase, comprising of chronometric cognitive evaluation. 


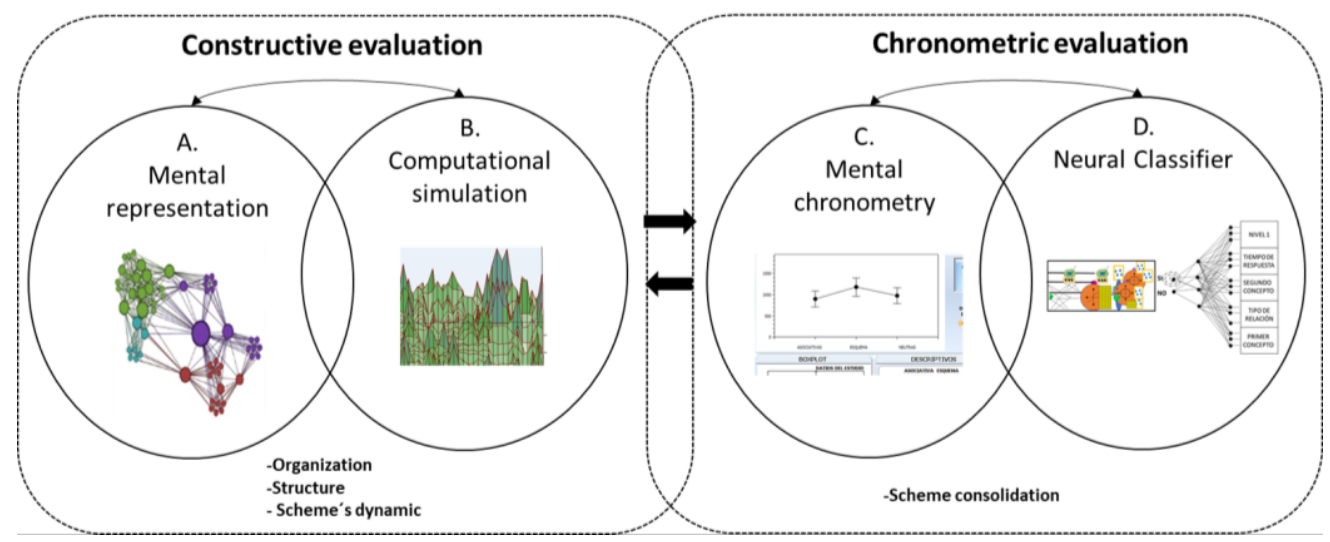

Figure 1: The chronometric constructive cognitive learning evaluation model

The NSN technique was proposed by Figueroa et al. (1976), who defined it as a mental representation technique for exploring the formation of meaning. According to Figueroa-Nazuno (2007), the NSN technique is underpinned by the memory theory which postulates that the formation of meaning is a constructive and reconstructive process that completely depends on the individual who constructs the meaning. This process of signifying reality or knowledge implies that people cognitively elaborate the interpretation they give to knowledge beyond the free association of concepts.

When applying the NSN technique, participants are required to define a series of concepts (objectives) through nouns, verbs, adjectives, or pronouns called definers within a predefined time limit, after which they must rate the degree of quality of each definer they provided. Figueroa-Nazuno (2007) emphasized that this metric facilitates comparison of meanings across groups and over time.

The NSN focuses on exploring the knowledge schema's organization and structure. In this regard, Lopez and Theios (1992) stated that the NSN can provide information on the semantic richness that the natural network holds, denoted as J-value. The J-value is the number of different definers the participants related to the knowledge schema measured. The relevance of each defining concept can also be ascertained according to participants' perception through the semantic weight (M-value) assigned to each definer by the participants. It is also possible to identify groups of concepts with the highest M-value, known as SAM group (Semantic Analysis of M-value). Other indicators that can be obtained are the occurrence frequency (F-value) of the definers across the network, and the semantic distance or G-value, which is the difference between the highest and the lowest M-value in the SAM group divided by the number of definers in the SAM group minus 1 .

In addition, Lopez-Ramirez (personal communication, August 9th, 2014) proposed including the inter-response time or (IRT), which is the time the participant requires to recover the definers from their memory. Further details on this analysis can be found in the article published by Morales-Martinez and Santos-Alcantara (2015). On the other hand, Lopez and Theios (1992) proposed extracting connectivity indicators using a neural network based on the strategy 
developed by Rumelhart et al. (1986). Lopez and Theios calculated the association weights between the concepts of the natural semantic network using a Bayesian formula (see method section), thus demonstrating that it is possible to explore the schematic behavior of concepts within the neural network by manipulating their activation.

The C3-LEM's second phase, chronometric cognitive evaluation, consists of experiments based on the paradigm of semantic facilitation, which are conducted to observe the degree of consolidation of information in memory. The semantic priming paradigm suggests that word recognition can be facilitated or inhibited by the information that precedes it. For example, in lexical decision studies, participants are presented with word pairs, and the time required to recognize the second word is measured. Here, it is assumed that the information networks related semantically to the first word will be activated in the person's memory. This activation of the evaluated schema will have an effect on the speed with which the second word presented will be recognized. Hence, if the two words are related, the recognition time will be shorter than if they are semantically unrelated. Lopez and Theios (1992) proposed that, aside from semantic priming, schematic priming could also exist, whereby two words connected by a specific knowledge schema, rather than by a general semantic relationship, would produce different reaction times than words that have other types of semantic relationships (e.g., associative, categorical).

In extant studies, the C3-LEM was shown to be useful for assessing learning schemas in various knowledge domains, including psychology, engineering, biology, and physics at different educational levels (see, e.g., Gonzalez et al., 2018a, 2018b; Morales, 2020; Morales-Martinez et al., 2020; Lopez-Ramirez et al., 2015; Morales-Martinez et al., 2018; Urdiales-Ibarra et al., 2018). The data obtained from these studies suggest that, when academic learning occurs, it induces changes in the organization and structure of the knowledge schema that is the object of learning. Determining the cognitive properties (structural, organizational, temporal, and dynamic) of medical knowledge acquisition process is important for generating a more detailed map not only of what students learn, but also of how they give meaning to this knowledge, how they establish relationships among concepts, topics, and disciplines that they are learning, and how they integrate this knowledge in the execution of medical skills such as clinical reasoning.

Since in medical training the learning of the structure and functions associated with the human body is essential for the diagnosis of structural abnormalities related to a disease, and for appropriate patient management (Samarasekera et al., 2015), in this work, we focus on the cognitive nature of learning complex subject matter, specifically the science of anatomy, by using the C3-LEM to determine the cognitive attributes involved in the anatomical knowledge students acquire. To meet this study objective, we aimed to elucidate the cognitive features of the human anatomy knowledge schema acquired by first-year medical students enrolled for a second time in the anatomy course. 


\section{Method}

\subsection{Study Overview}

Lopez and Theios (1992) suggested that the knowledge a person has on a specific topic can be measured through representation techniques and mental chronometry, both of which derive from cognitive science. In this context, the knowledge state could be defined as the semantic richness of a knowledge schema (i.e., the number of conceptual nodes), the schemata behavior's type, the relationships among the nodes, and the time required to activate these information nodes. Transferring these concepts to the educational field, the knowledge state with which a student enters or ends an academic course can be measured through indicators pertaining to the organization and structure of the acquired knowledge schema. The authors adopted this strategy, which involved a series of experiments rooted in cognitive science based on the C3-LEM which were designed to assess the state of medical knowledge students enrolled for a second time in an anatomy course possess.

\subsection{Participants}

The study sample comprised of 52 first-year medical students enrolled for a second time in an anatomy course (43 women and 9 men). The participants' age ranged from 18 to 27 years $(M=19.7, S D=1.6)$. All participants were volunteers and gave their informed consent. The participants were chosen for the study through non-probability sampling.

\subsection{Study Design}

The cognitive dimension of academic learning pertains to changes in the organization, structure, temporality, and dynamics of the acquired knowledge schema. To measure these schematic properties, the authors adopted a qualitative and quantitative mixed-methods research design based on the C3-LEM, which involved use of three cognitive science study techniques or paradigms.

First, the NSN technique developed by Figueroa et al. (1976) was adopted to measure the organizational and structural properties of the participants' anatomy knowledge schemata. The procedure met the SASO application guidelines (Lopez \& Theios, 1992) and followed the EVCOG approach (Lopez \& Morales, 2019; Morales-Martínez \& Lopez-Ramirez, 2016). Next, the authors observed the anatomy schemata's behavior through a constraint satisfaction neural network, which involved applying computational simulation to the data in the preceding phase. Finally, the degree of anatomy schema consolidation in the participants' memory was explored through a semantic priming experiment with reaction time and participants' response as the independent variables.

\subsection{Instruments and Materials}

In line with the C3-LEM design, the researchers applied the Morales-Martinez's (2015) protocol to obtain the target concepts and definers used in the first study phase. For this purpose, anatomy teachers provided ten most relevant target concepts that students should learn as a part of the anatomy course (anatomy, headneck, nervous system, upper limb, thorax, abdomen, upper limb, pelvis, organs and systems, and diagnosis) which were used in the metal representation task. The EVCOG software was used to design and administer the tasks, capture the data, 
and analyze the NSN results, while GEPHI software (Bastian et al., 2009) was adopted to conduct visual analysis of the NSN data. The EVCOG system allowed us to extract the connectivity matrix and perform the computational simulation on the NSN data. Finally, to design the semantic priming experiment, the researchers introduced 45 word pairs, 15 of which were relevant to the anatomy course (e.g., supination-scoliosis, sphenoid-subclavian, prolactin-brachial) into the EVCOG system.

\subsection{Procedure}

As noted earlier, this study comprised of three phases. It commenced by extending an open invitation to first-year medical students enrolled for a second time in the anatomy course to participate in a cognitive science investigation. The students that voluntarily gave their informed consent attended a group session as a part of which they completed the NSN test (Figueroa et al., 1976) based on the procedure described by Lopez (1996). They were presented with ten target concepts deemed most relevant by anatomy teachers one by one on a computer screen and had 60 seconds to define each target concept using verbs, nouns, adjectives, and pronouns (definers) of their choice. Once all ten concepts had been defined, they scored each definer using a 1-10 scale, whereby 1 indicated that the definer was only slightly related to the target concept and 10 meant that the definer was highly related to the target concept.

In the second study phase, the authors carried out a computer simulation using the thus generated NSN data following the procedure proposed by Lopez and Theios (1992). These authors used a neural network of constraint satisfaction similar to that described by Rumelhart et al. (1986) to emulate the behavior of an emerging schema. In general way, Lopez and Theios calculated the SASO connectivity matrix between the concepts was obtained by applying Equation 1 below:

$$
W_{\text {IJ }}=-1 n\left\{[p(X=0 \& Y=1) p(X=1 \& Y=0)]^{*}[p(X=1 \& Y=1) p(X=0 \& Y=0)]^{-1}\right\}
$$

where $X$ and $Y$ represent a pair of concepts that are associated, with $p(X=1 \& Y$ $=0$ ) denoting the joint probability that $X$ appeared but $Y$ did not appear in a SAM. The values for $p(X=0 \& Y=1)$ and $p(X=0 \& Y=0)$ were similarly defined and were computed in the same manner. The term $p(X=1 \& Y=1)$ was calculated considering the hierarchical modulation of M-values in SAM groups and their interconnectivity in neural network computations.

The study culminated with the application of the semantic priming experiment requiring students to perform a lexical decision task. After a practice session, provided to allow familiarize the students with the task, they were presented with 45 experimental trials chosen at random. Each experimental trial consisted of an experimental sequence of four stimuli, whereby a dot appeared on a computer screen for $500 \mathrm{~ms}$, followed by the first word (prime) for $250 \mathrm{~ms}$, a blank space for $50 \mathrm{~ms}$, and the last word (target), which remained on the screen until the participant provided an answer (by stating whether the target was or was not a word). 


\section{Results}

\subsection{The First Phase Results: The RSN Study}

The NSN values were computed using the metric suggested by Lopez and Theios (1992) and a summary of the obtained values is presented in Table 1. It can be observed that the target concept with the highest number of definers (J-value) was upper limb, followed by thorax and nervous system. In contrast, the target with the lowest number of definers or smallest semantic richness was pelvis. On the other hand, the definer with the highest occurrence frequency was muscles followed by bones, arteries, brain, organs, heart, lungs, liver, and pancreas.

The ten definers with the highest semantic relevance (M-value) throughout the NSN were ribs, human body, heart, intestines, lungs, hands, study, radius, and humerus. Furthermore, the definers that required less inter-response time (IRT) were legs, arms, joints, viscera, hands, cavities, skull, foot, forearm, and human body. It is interesting to observe that, in the relation to the thorax concept, the three highest M-values and the three lowest IRT definers were the same: heart, lungs, and ribs. A similar observation could apply to the lower limb (legs, foot, femur).

Table 1: SAM groups of the anatomy schemata obtained from the participants

\begin{tabular}{|c|c|c|c|c|c|c|c|}
\hline \multicolumn{4}{|c|}{ Anatomy } & \multicolumn{4}{|c|}{ Head-Neck } \\
\hline $\mathbf{F}$ & Definer & $\mathbf{M}$ & IRT & $\mathbf{F}$ & Definer & $\mathbf{M}$ & IRT \\
\hline 1 & Human body & 339 & 19 & 3 & Brain & 188 & 22 \\
\hline 1 & Study & 231 & 19 & 6 & Muscles & 173 & 18 \\
\hline 2 & Organs & 159 & 31 & 1 & Eyes & 164 & 32 \\
\hline 1 & Systems & 130 & 34 & 1 & Skull & 136 & 16 \\
\hline 1 & Structure & 117 & 33 & 1 & Mouth & 100 & 25 \\
\hline 6 & Muscles & 112 & 30 & 1 & Nose & 93 & 42 \\
\hline 1 & Science & 93 & 21 & 4 & Bones & 92 & 33 \\
\hline 4 & Bones & 84 & 34 & 3 & Arteries & 87 & 42 \\
\hline 1 & Dissection & 77 & 31 & 1 & Ears & 83 & 45 \\
\hline 1 & Regional & 77 & 29 & 1 & Triangles & 64 & 24 \\
\hline & J-value: 410 & \multicolumn{2}{|c|}{ G-value: 26.20} & \multicolumn{2}{|c|}{ J-value: 436} & \multicolumn{2}{|c|}{ G-value: 12.40} \\
\hline \multicolumn{4}{|c|}{ Nervous system } & \multicolumn{4}{|c|}{ Upper limb } \\
\hline $\mathbf{F}$ & Definer & $\mathbf{M}$ & IRT & $\mathbf{F}$ & Definer & $\mathbf{M}$ & IRT \\
\hline 3 & Brain & 286 & 18 & 1 & Hands & 232 & 15 \\
\hline 1 & Neurons & 222 & 20 & 1 & Radius & 230 & 23 \\
\hline 1 & Nerves & 198 & 25 & 1 & Humerus & 229 & 20 \\
\hline 1 & Spinal cord & 183 & 26 & 1 & Arms & 224 & 13 \\
\hline 1 & Cerebellum & 173 & 36 & 1 & Ulna & 198 & 29 \\
\hline 1 & Ganglia & 144 & 27 & 1 & Phalanges & 196 & 37 \\
\hline 1 & Pons & 105 & 31 & 1 & Forearm & 154 & 19 \\
\hline 1 & Central & 92 & 25 & 6 & Muscles & 133 & 31 \\
\hline 1 & Peripheral & 88 & 27 & 1 & Carpus & 115 & 32 \\
\hline 1 & Parasympathetic & 84 & 40 & 1 & $\begin{array}{l}\text { Brachial } \\
\text { plexus }\end{array}$ & 110 & 36 \\
\hline
\end{tabular}

Note: J-value $=$ semantic richness, G-value $=$ semantic density, $\mathrm{F}=$ occurrence frequency, $\mathrm{M}=$ semantic weight, IRT = inter-response time 
Table 1: SAM groups of the anatomy schemata obtained from the participants (continued)

\begin{tabular}{|c|c|c|c|c|c|c|c|}
\hline \multicolumn{4}{|c|}{ Thorax } & \multicolumn{4}{|c|}{ Abdomen } \\
\hline $\mathbf{F}$ & Definer & $\mathbf{M}$ & IRT & $\mathbf{F}$ & Definer & $\mathbf{M}$ & IRT \\
\hline 2 & Heart & 385 & 21 & 1 & Intestines & 249 & 25 \\
\hline 1 & Ribs & 385 & 24 & 1 & Stomach & 229 & 19 \\
\hline 2 & Lungs & 357 & 23 & 6 & Muscles & 195 & 23 \\
\hline 1 & Breastbone & 228 & 34 & 2 & Liver & 193 & 32 \\
\hline 1 & Mediastinum & 146 & 28 & 2 & Organs & 122 & 17 \\
\hline 1 & Protection & 142 & 36 & 1 & Viscera & 96 & 14 \\
\hline 1 & Diaphragm & 98 & 32 & 2 & Pancreas & 82 & 39 \\
\hline 1 & Clavicle & 93 & 46 & 1 & Kidneys & 66 & 44 \\
\hline 3 & Arteries & 85 & 40 & 1 & Gallbladder & 59 & 46 \\
\hline \multirow[t]{2}{*}{1} & Vertebrae & 80 & 33 & 1 & Cavities & 58 & 16 \\
\hline & J-value: 453 & \multicolumn{2}{|c|}{ G-value: 30.50} & & J-value: 383 & \multicolumn{2}{|c|}{ G-value: 19.10} \\
\hline \multicolumn{4}{|c|}{ Lower limb } & \multicolumn{4}{|c|}{ Pelvis } \\
\hline $\mathbf{F}$ & Definer & $\mathbf{M}$ & IRT & $\mathbf{F}$ & Definer & $\mathbf{M}$ & IRT \\
\hline 1 & Femur & 176 & 21 & 4 & Bones & 156 & 21 \\
\hline 1 & Legs & 159 & 10 & 6 & Muscles & 76 & 31 \\
\hline 1 & Foot & 153 & 17 & 1 & Sacrum & 73 & 21 \\
\hline 6 & Muscles & 152 & 23 & 1 & Ilium & 61 & 26 \\
\hline 1 & Tibia & 128 & 24 & 1 & Lower & 58 & 25 \\
\hline 4 & Bones & 121 & 24 & 1 & Bladder & 54 & 44 \\
\hline 1 & Walk & 114 & 23 & 1 & Iliac crest & 48 & 28 \\
\hline 1 & Movement & 107 & 34 & 1 & Ligaments & 43 & 46 \\
\hline 1 & Fibula & 82 & 34 & 3 & Arteries & 42 & 54 \\
\hline 1 & Knees & 81 & 22 & 1 & Articulation & 40 & 28 \\
\hline
\end{tabular}

\begin{tabular}{llccclccc}
\hline & J-value: 441 & \multicolumn{2}{c}{ G-value: 9.50} & \multicolumn{4}{c}{ J-value: 278} & G-value: 11.60 \\
\hline \multicolumn{3}{c}{ Organs-systems } & \multicolumn{4}{c}{ Diagnosis } \\
\hline F & \multicolumn{1}{c}{ Definer } & M & IRT & F & Definer & M & IRT \\
\hline 2 & Heart & 176 & 22 & 1 & Disease & 159 & 25 \\
1 & Functions & 163 & 22 & 1 & Patient & 147 & 19 \\
1 & Respiratory & 151 & 26 & 1 & Laboratory & 141 & 29 \\
2 & Lungs & 125 & 30 & 1 & Symptoms & 116 & 31 \\
2 & Liver & 120 & 28 & 1 & Treatment & 106 & 30 \\
1 & Digestive & 119 & 28 & 1 & Signs & 97 & 29 \\
1 & Set & 117 & 13 & 1 & Knowledge & 89 & 35 \\
3 & Brain & 117 & 42 & 1 & Doctor & 84 & 35 \\
1 & Nervous & 86 & 33 & 1 & Questions & 80 & 30 \\
2 & Pancreas & 91 & 33 & 1 & Outcome & 73 & 39 \\
\hline & J-value: 401 & \multicolumn{2}{c}{ G-value: 8.50} & \multicolumn{3}{c}{ J-value : 376} & G-value: 7.40
\end{tabular}

Note: $\mathrm{J}$-value $=$ semantic richness, $\mathrm{G}$-value $=$ semantic density, $\mathrm{F}=$ occurrence frequency,

$\mathrm{M}=$ semantic weight, IRT = inter-response time 
The visual analysis results presented in Figure 2 indicate that the diagnostic node has no connections with any of the other network's target concepts. The nodes related to nervous system and thorax exhibit very low connectivity compared with other conceptual members of the anatomy schema. For example, nervous system had only two conceptual links. Moreover, the target concepts such as organs-systems, upper limb, and thorax are partially disconnected from the complete anatomy schema. With eight conceptual links, the head-neck node exhibits the highest degree of connectivity within the schema.
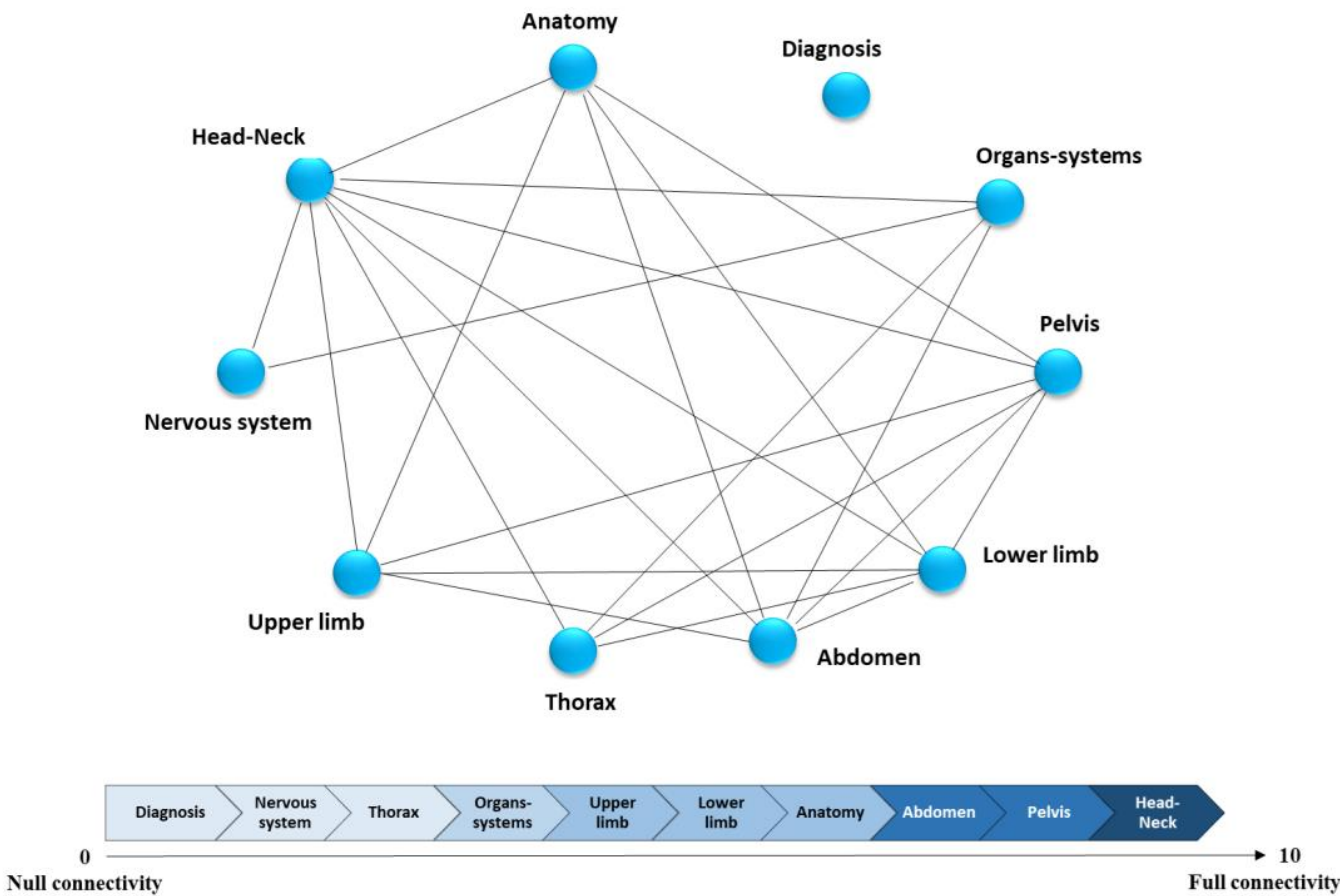

Figure 2: Connectivity graph of the ten target concepts in the anatomy schema and the degree of connectivity in each one

The GEPHI analysis (Bastian et al., 2009) indicates that the participants organized the anatomy course information into six modules, as shown in Figure 3. The first conceptual module involved 30\% (24) of the natural semantic network's main definers, which are connected to the anatomy schema through the muscles concept. This module involved three subgroups, the first of which includes the definers (e.g., legs, walking, movement) linked with muscles through bones. The second group consists of the definers (e.g., human body, kidneys, cavities) that are linked to muscles through organs. The last group included the definers (structures, regional, systems, dissection, science, and study) connected with muscles. 


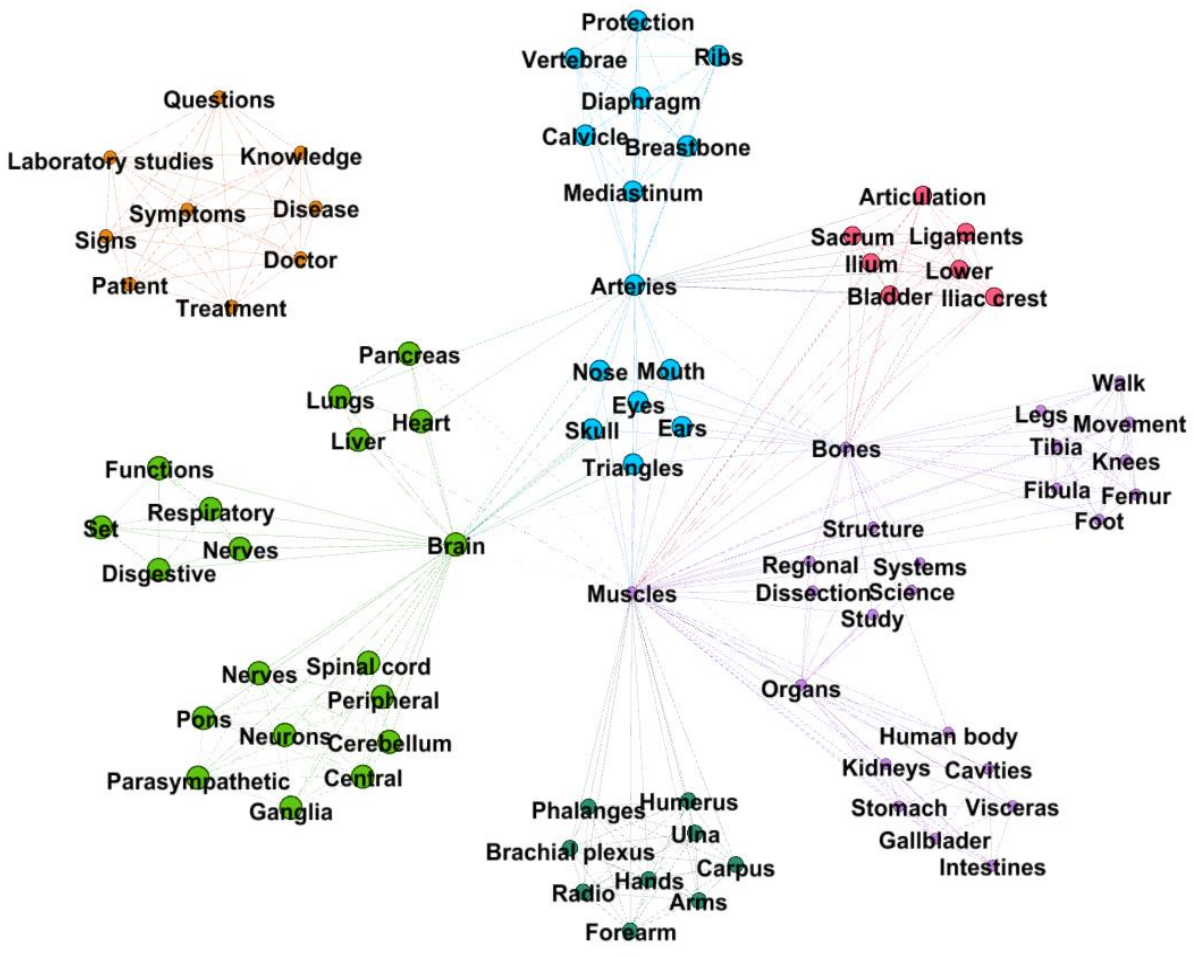

Figure 3: The participants' structure and organization of the information obtained at the end of the anatomy course

The second conceptual module contains 19 definers (23\%) connected to the anatomy schema through the brain concept. Three groups formed this module, respectively including concepts related to organs (pancreas, lungs, heart, liver); definers that mostly indicate systems' functions (functions, respiratory, joint, digestive, nervous); and definers related to brain structures (spinal cord, nerves, peripheral, pons, neurons, cerebellum, parasympathetic, central, ganglion).

The third conceptual module included 14 definers $(17 \%)$ connected to the anatomy schema through the arteries concept. This module involves two subsets pertaining to (1) concepts such as protection, vertebrae, ribs, and diaphragm, and (2) definers such as nose, mouth, eyes, skull, and ears. This latter group connects to Module 2 via the brain concept. The fourth conceptual module contained nine definers $(11 \%)$ related to an upper limb (e.g., phalanges, humerus, ulna, brachial plexus, hands, arms) connected to the schema through the muscle concept. The fifth group consists of nine definers $(10 \%)$ related to diagnosis (e.g., questions, laboratory studies, knowledge, symptoms). Note that the diagnosis module is independent of the remainder of the semantic network. The sixth group consists of seven definers $(9 \%)$ associated with the pelvis concept (e.g., sacrum, ligaments, ilium, inferior, bladder, iliac crest), and they connected to the rest of the anatomy schema through arteries, bones, and muscles.

The most relevant nodes involved in the semantic network integration were muscles-bones-organs, brain, and arteries. 


\subsection{The Second Phase Results: A Computer Simulation Study}

To carry out the computational simulation of the anatomy schema, the concepts were activated considering the IRT, the M-value, and the conceptual relevance level derived from the GEPHI analysis (Figure 3). The results indicated that the definers that produced a greater number of co-activations were ribs (concept with the highest $M$ value), gallbladder (concept with the highest IRT), joints (concept with the lowest M-value), arteries (concept which was central to the third GEPHI module) and brain (central concept in the second GEPHI module). The definers with the lowest number of co-activated concepts were leg (concept that obtained the lowest IRT) and muscles (central concept in the first GEPHI module), as shown in Figure 4.

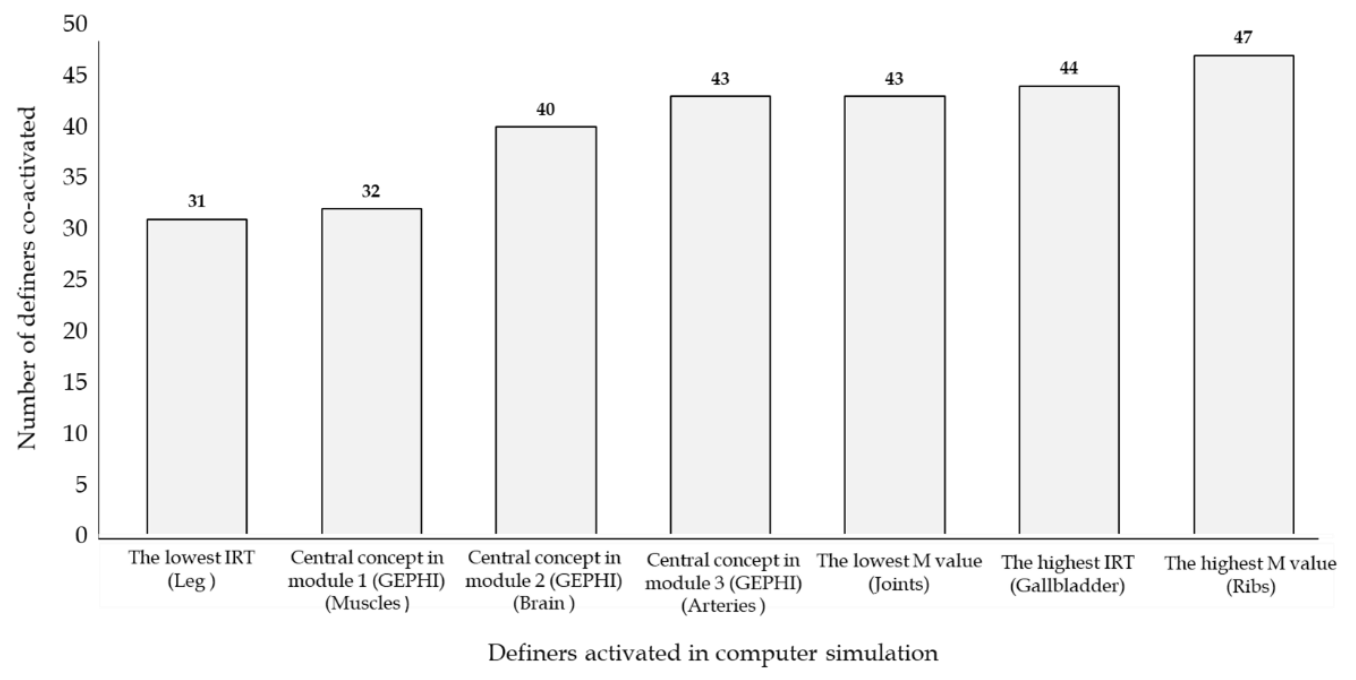

Figure 4: The number of co-activated concepts for each definer concept activated during the computational simulations

Table 2 shows the activation of ribs and gallbladder co-activated some concepts related to the upper limb (e.g., radius, humerus, arms). Each one of these definers (ribs and gallbladder) in isolation co-activated $57 \%$ of the definers linked to the anatomy schema through the pelvis concept. On the other hand, activation of ribs co-activated the $63 \%$ of the definers linked to the anatomy schema through the brain concept, while the activation of gallbladder co-activated $42 \%$ of this same group. 
Table 2: Co-activation of definers when ribs and gallbladder were activated

\begin{tabular}{|c|c|c|c|c|c|}
\hline \multirow[b]{2}{*}{ Definer } & \multicolumn{2}{|c|}{ Activated Concepts } & \multicolumn{3}{|c|}{ Activated Concepts } \\
\hline & Ribs & Gallbladder & Definer & Ribs & Gallbladder \\
\hline Femur & - & - & Ribs & * & $*$ \\
\hline Bones & * & - & Breastbone & * & - \\
\hline Muscles & * & - & Mediastinum & - & * \\
\hline Legs & - & - & Protection & - & * \\
\hline Foot & * & * & Diaphragm & * & * \\
\hline Tibia & * & - & Arteries & * & * \\
\hline Walk & * & * & Clavicle & * & - \\
\hline Movement & * & - & Vertebrae & - & * \\
\hline Fibula & - & - & Eyes & - & * \\
\hline Knees & * & & Skull & * & * \\
\hline Study & - & * & Mouth & - & - \\
\hline Systems & - & * & Nose & - & - \\
\hline Structures & * & * & Ears & - & * \\
\hline Science & - & - & Triangles & * & - \\
\hline Dissection & - & * & Hands & - & * \\
\hline Regional & * & * & Radius & * & - \\
\hline Human body & * & * & Humerus & * & * \\
\hline Bowels & * & * & Arms & * & * \\
\hline Stomach & * & * & Ulna & - & * \\
\hline Organs & * & - & Phalanges & * & - \\
\hline Viscera & - & - & Forearm & - & - \\
\hline Kidneys & * & - & Carpus & * & * \\
\hline Gallbladder & * & * & Brachial plexus & * & * \\
\hline Cavities & - & * & Diseases & - & - \\
\hline Brain & * & - & Patient & * & * \\
\hline Heart & - & - & Studies & * & * \\
\hline Lungs & - & - & Symptoms & - & * \\
\hline Liver & - & - & Treatment & - & - \\
\hline Pancreas & * & * & Signs & - & * \\
\hline Function & - & * & Knowledge & - & - \\
\hline Respiratory & * & - & Doctor & - & - \\
\hline Digestive & * & - & Questions & - & - \\
\hline Set & * & - & Sacrum & * & * \\
\hline Nervous & * & - & Ilium & * & * \\
\hline Neurons & - & * & Lower & * & * \\
\hline Nerves & - & - & Bladder & - & * \\
\hline Spinal cord & * & * & Iliac crest & * & - \\
\hline Cerebellum & * & * & Ligaments & - & - \\
\hline Ganglia & * & - & Joints & - & - \\
\hline Pons & * & * & Result & * & * \\
\hline Central & * & - & & & \\
\hline Peripheral & * & * & & & \\
\hline Parasympathetic & - & * & & & \\
\hline
\end{tabular}

Figure 5 shows the connectivity weights obtained for the semantic network of the anatomy course. Note that a conceptual activation group is characterized across the diagonal, and several small activation groups are scattered across the surface of connectivity weights. 


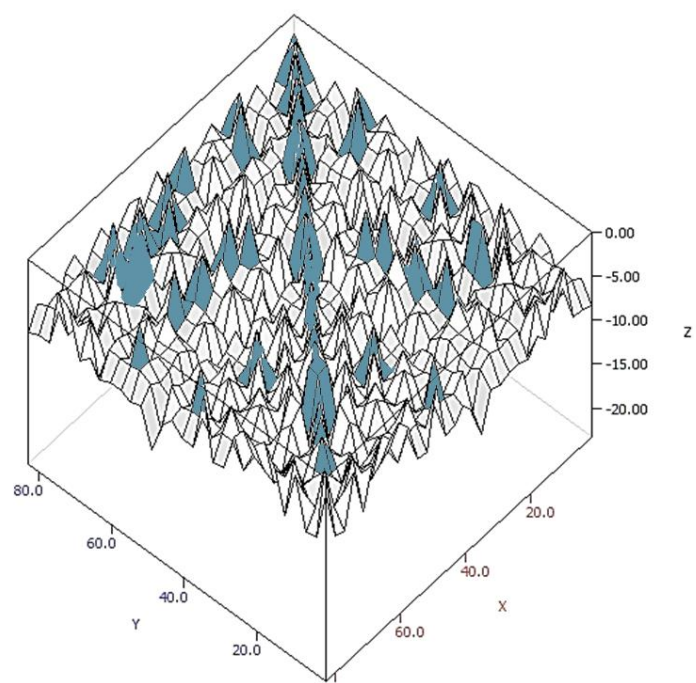

Figure 5: The activation pattern of the anatomy schema developed by students enrolled for a second time in an anatomy course

\subsection{The Third Phase Results: Semantic Priming Study}

A repeated-measures ANOVA was carried out on the participants' data, revealing a statistically significant difference between word pairs depending on the relationship type $\left[F(2,102)=108.937, p \leq .001, \eta^{2}=.68\right]$. As shown in Figure 6 , the participants experienced a greater interference effect in the word recognition task when presented with pairs associated with the anatomy schema compared to pairs with an associative relationship or without a relationship.

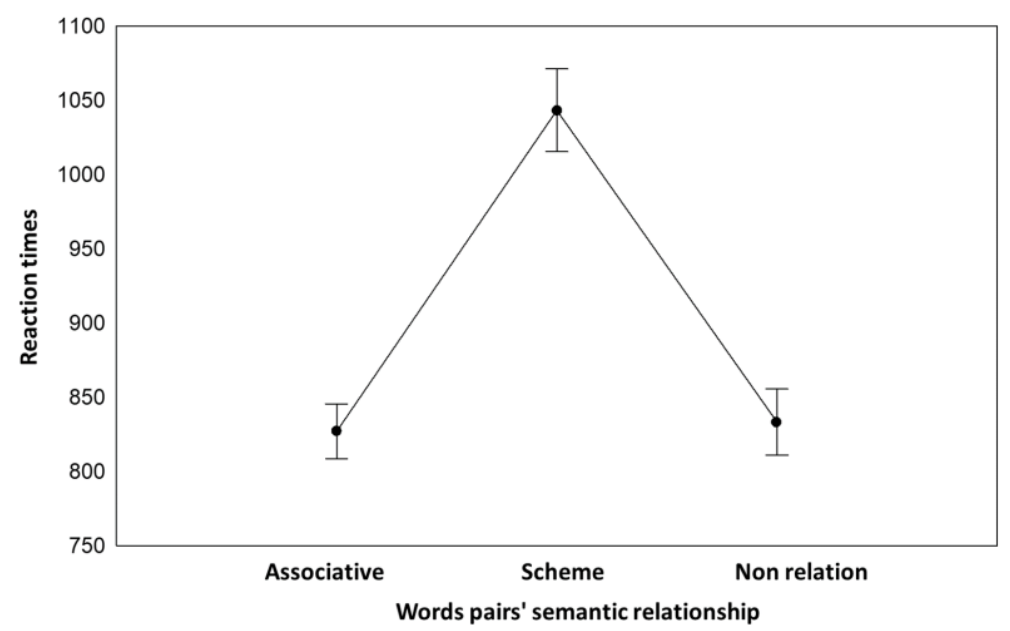

Figure 6: Participants' word recognition times in a lexical decision task

\section{Discussion}

The aim of the present study was to determine the characteristics of the anatomy information processing style adopted by first-year medical students enrolled for a second time in the anatomy course. In the first study phase (representation of anatomy knowledge), the authors measured the organizational and structural properties of the knowledge schema that students acquired in the anatomy course. As shown in Table 1, the participants developed a rich semantic network 
characterized by a wide diversity of information nodes. However, the structure and organization of the information presented in the anatomy course was inadequate (Figure 2 and 3).

The knowledge schema structure related to anatomy was fractured, as shown in Figure 3, as several targets such as diagnostic, nervous system, organs and systems, and thorax were disconnected from other anatomy concepts. Similar information integration patterns have also been observed in students majoring in different fields who have not achieved passing grades (see Morales-Martinez et al., 2018) or who are just starting a new course (Urdiales-Ibarra et al., 2018).

Therefore, the present study findings suggest that the participants are unable to consider the course content from a broader perspective, that is, they cannot completely infer the configuration of the general course outline. The structure of the knowledge schema can be confusing for these students in the same way that it seems to be blurry for students starting an unfamiliar course. In relation to the difficulties observed in the schema organization, the NSN analysis, GEPHI analysis (see Figure 3), and computer simulation results (Table 2) pointed out that the anatomy schema developed by these students lacks a coherent organization, indicating that students had difficulties to relate the anatomy concepts taught in class.

To examine these findings further, it is worth considering the concepts characterized by less connectivity in the anatomy NSN. For instance, the diagnosis concept had no connectivity with the remaining target concepts, while nervous system was connected with only two of the target concepts (head-neck and organs-systems), as shown in Figure 2. In both cases, we conjectured that the importance attributed to the anatomy topics could influence this schema fragmentation, since diagnosis was presented during the course as a generalknowledge topic rather than a central part of the anatomy course. Consequently, students perceived this topic separately from the rest of the schema. The anatomy teachers informed us that, during instruction, discussions on diagnosis were not explicitly connected with the remaining anatomy concepts, which is reflected in the schema's conceptual nodes.

It is also possible that the broken schema observed in this study may be the result of an inadequate information integration strategy that makes it difficult for students to retrieve accurate information. In other words, students who did not get the passing grade in anatomy course may struggle to form a coherent and structured schema, as would be the case for novice students (e.g., Urdiales-Ibarra et al., 2018). In order to explore this possibility, it is necessary to compare these results with those achieved by students at the beginning of the course, as well as by those that have obtained passing grades in the anatomy course.

In the second study phase, the authors explored the behavior of the anatomy schema. In general, the computational simulation results indicated that the activation of some nodes of the anatomy-related network seems to be carried out in a dispersed manner, as shown in Figure 5 and Table 2. This finding supports 
the idea that the participants had difficulties in organizing the concepts learned in the anatomy class.

An interesting result that emerged from this investigation pertained to the definer with the highest M-value (ribs) which co-activated the greatest number of concepts in the semantic network (Figure 4). Although, as in the study conducted by Morales-Martinez and Santos-Alcantara (2015), the concepts with the highest M-values did not appear with the lowest IRTs, these tended to appear between the 3rd and 4th position of the NSN. Therefore, we hypothesize that the M-value is more closely related to the schema organization than to the ease of access to the information stored in that mental structure. For example, activation of ribs yielded a better organization in the computational simulation than the activation of gallbladder. This result is particularly relevant to the theory of mental representation of knowledge, since the M-value remains insufficiently explored in academic research.

Although, activation of gallbladder co-activated almost as many concepts as ribs (Figure 4), the type of relationship that linked these concepts is not very clear. For example, activation of gallbladder co-activated the eye concept, which would suggest that the students used schemas from other knowledge domains, such as pathophysiology. A similar observation was made by Gonzalez et al. (2018a), who noted that activation of certain concepts in some cases co-activates concepts from semantic categories different from the measured schema. This result suggests that computational simulations can be very useful in identifying implicit information embedded within schemas, which is in accordance with the idea that schemata can embed other schemas. On the other hand, as gallbladder was the definer with the highest IRT (see Figure 4 and Table 1), this may suggest that the establishment of relationships between concepts that apparently do not have a clear organization can delay the access to relevant information.

The final study phase comprised of a mental chronometry experiment, allowing us to explore the temporal property of the acquired anatomy schema. The results revealed that the participants experienced interference in the recognition of words related to the anatomy schema (Figure 6). This same finding was reported for other students who did not obtain passing grades (Morales-Martinez et al., 2020), as well as for novice students (Morales-Martinez et al., 2020; Morales-Martinez et al., 2018; Morales-Martinez et al., 2018; Urdiales-Ibarra et al., 2018).

Interference in the recognition of schematic words suggests that the students did not store the anatomy information as a new semantic category. Authors of other studies in different domains (e.g., Gonzales et al., 2013; Lopez et al., 2014; Lopez et al., 2015; Morales-Martinez et al., 2020; Morales-Martinez et al., 2014; MoralesMartinez et al., 2018) similarly found that, when students form schemas or new categories of knowledge in their long-term memory due to course attendance, this tends to result in a schematic facilitation effect (Gonzalez et al., 2018a; Lopez \& Tehios, 1992). From this perspective, we can deduce that the interference in the recognition of anatomy schematic words suggests that the study participants did 
not consolidate the information nodes related to anatomy into a unified knowledge schema.

The findings yielded by the present study are in accordance with the evidence reported by other authors, suggesting that C3-LEM is a useful tool for identifying the state of knowledge students in diverse disciplines possess (see Morales, 2020; Morales-Martinez et al., 2020; Morales-Martinez et al., 2018; Morales-Martinez et al., 2018; Urdiales-Ibarra et al., 2018). In other words, cognitive studies involving mental representation tasks, computational simulation, and mental chronometry experiments provide valuable information on the cognitive properties of the mental structures that students construct during training in a specific domain of knowledge. However, to continue exploring the utility of this approach in evaluation of learning, comparison groups should be included in the study design and the measurements should be conducted at different points in time during the course.

\section{Conclusions}

The study findings indicate that the students enrolled for a second time in the anatomy course had difficulties in the information integration and recognition of concepts studied during the course. The study participants seemed to struggle with perceiving the course's general organization, despite their ability to recognize links among different concepts. In other words, although participants got the content of the anatomy course, they could not integrate the acquired information in a unified anatomy schema or a new semantic category.

These findings suggest that C3-LEM was successful in identifying inappropriate patterns in the learned schematic behavior. These cognitive techniques could be a handy formative tool since they provide some indicators of students' ability to identify and integrate the conceptual nodes central to the subject, which would allow the implementation of corrective processing strategies before the exams.

Also, the cognitive tools will be useful to analyze whether the students can integrate all knowledge gained and use it to face the challenges of professional life. For example, since the computational simulation studies seem to provide information on the implicit use of other schemas to build the knowledge acquired in a course, these techniques can be used to ascertain whether students can integrate the knowledge they acquired in other subjects in a single approach.

Reaction time studies can identify students who have difficulties in consolidating the information they store in their memory. Thus, these studies' obtained temporal parameters could indicate the robustness of each student's learning process.

In sum, cognitive studies such as those proposed in the C3-LEM could help to diagnose the regularities and irregularities in the organization and structure of studied schemas. This information will empower teachers and researchers to propose strategies that contribute to making the teaching and learning process more effective in the medical field. 


\section{References}

Anderson, J. R. (1976). Language, memory, and thought. Lawrence Erlbaum Associates.

Arieli-Attali, M. (2013, October 20-25). Formative assessment with cognition in mind: The cognitively based assessment of, for and as learning [Paper presentation]. 39th Annual Conference: Educational Assessment 2.0: Technology in Educational Assessment, Tel Aviv, Israel. Retrieved from https://www.iaea.info/conferenceproceedings/

Bastian, M., Heymann, S., \& Jacomy, M. (2009, May 17-20). Gephi: An Open Source Software for Exploring and Manipulating Networks [Paper presentation]. Association for the Advancement of Artificial Intelligence, Third International AAAI Conference on Weblogs and Social Media, San Jose California, United States. Retrieved from https://gephi.org/publications/gephi-bastian-feb09.pdf

Boulet, J. R., \& Durning, S. J. (2019). What we measure . . and what we should measure in medical education. Medical Education, 53(1), 86-94. https://doi.org/10.1111/medu.13652

Bower, G. H. (1975). Cognitive psychology: An introduction. In W. K. Estes (Ed.), Handbook of learning and cognitive processes: Vol. 1. Introduction to concepts and issues (pp. 2580). Lawrence Erlbaum Associates.

El-Yassin., H. D. (2015). Integrated assessment in medical education. Journal of Contemporary Medical Sciences, 1(4), 36-38. Retrieved from http://www.jocms.org/index.php/jcms/article/view/51

Epstein, R. M. (2007). Assessment in medical education [Editorial]. New England Journal of Medicine, 356(4), 387-396. Retrieved from https://www.pennem.com/wpcontent/uploads/N-Engl-J-Med-2007-Epstein.pdf

Ferris, H., \& O'Flynn, D. (2015). Assessment in medical education; What are we trying to achieve? International Journal of Higher Education, 4(2), 139-144. http://dx.doi.org/10.5430/ijhe.v4n2p139

Figueroa-Nazuno, J. G. (2007, October 24-25). El significado de las Redes Semánticas Naturales: Y la tradición oral, 20 años después [The meaning of Natural Semantic Networks: And oral tradition, 20 years later] [Paper presentation]. Primer Simposium Internacional: Cognición y Representación del Conocimiento. Monterrey, Nuevo Leon, Mexico.

Figueroa, J. G., Gonzalez, E. G., \& Solis, V. M. (1976). An approach to the problem of meaning: Semantic networks. Journal of Psycholinguistic Research, 5(2), 107-115. https://doi.org/10.1007/BF01067252

Friedman, C. P., \& Wyatt, J. (2006). Evaluation methods in biomedical informatics (2nd ed.). Springer Science \& Business Media. https:/ / doi.org/10.1007/0-387-30677-3

Gonzalez, C. J., Lopez, E. O., \& Morales, G. E. (2018a, May 26-28). Self-organized schemata behavior and meaning formation to evaluate e-learning [Paper presentation]. The International Conference on Distance Education and Learning. Beijing, China. https:// doi.org/10.1145/3231848.3231877

Gonzalez, C. J., Lopez, E. O., \& Morales, G. E. (2018b, Jan 6-8). A cognitive tool to evaluate meaning formation of course contents: A learning-oriented assessment [Paper presentation]. The International Conference on Distance Education and Learning. Beijing, China. https://doi.org/10.1145/3231848.3231877

Jimaa, S. (2011). The impact of assessment on students' learning. Procedia - Social and Behavioral Sciences, 28, 718-721. https://doi.org/10.1016/j.sbspro.2011.11.13

Lopez, R. E. O. (1989, December 1-6). Sistema predictor de indice reprobatorio (SPIR) [Failure rate predictor system-SPIR] [Paper presentation]. IX Coloquio de Investigación. ENEP Iztacala, Mexico city, Mexico. 
Lopez, E. O. (1996). Schematically Related Word Recognition (Publication No. 9613356) [Doctoral dissertation, University of Wisconsin-Madison]. ProQuest Dissertations \& Theses Global.

Lopez, E. O., Morales, G. E., Hedlefs, I., \& Gonzalez, C. J. (2014). New empirical directions to evaluate online learning. International Journal of Advances in Psychology, 3(2), 40-47. https://doi.org/10.14355\&ijap.2014.0302.03.

Lopez-Ramirez, E. O., Morales-Martinez, G. E., Hedlefs-Aguilar, M. I., Gonzalez-Trujillo, C. J., \& Moreno-Meza, A. P. (2015). Nuevas direcciones empíricas en la investigación e innovación de tecnología educativa para la evaluación del aprendizaje en línea: Una aproximación conexionista [New empirical directions in educational technology research and innovation for online learning assessment: A connectionist approach]. Ciencia UANL, 18(71), 52-64.

Lopez-Ramirez, E. O., \& Morales-Martinez, G. E. (2019). Learning's constructivechronometric cognitive assessment model [Unpublished manuscript]. Institute of Research on the University and Education, National Autonomous University of Mexico.

Lopez, E. O, \& Theios, J. (1992). Semantic analyzer of schemata organization (SASO). Behavior Research Methods, Instruments, \& Computers, 24(2), 277-285. Retrieved from https://link.springer.com/content/pdf/10.3758/BF03203508.pdf

Miller, G. E. (1990). The assessment of clinical skills/competence/performance. Academic Medicine: Journal of the Association of American Medical Colleges, 65(9 Suppl), S63S67. https://doi.org/10.1097/00001888-199009000-00045

Morales-Martinez, G. E. (2015). Protocolo para la recolección de conceptos objetivo y definidores centrales y diferidos (PRECODECD): Un sistema de codificación de conceptos extraídos de las redes semánticas naturales [Protocol for the collection of objective concepts and central and deferred definers (PRECODECD): A coding system for concepts extracted from natural semantic networks] [Unpublished manuscript]. Institute of Research on the University and Education, National Autonomous University of Mexico.

Morales M. G. E. (2020). Sistema de evaluación cognitiva constructiva cronométrica del aprendizaje en linea y presencial [Online and face to face learning's constructivechronometric cognitive assessment system] [Manuscript submitted for publication]. Institute of Research on the University and Education, National Autonomous University of Mexico.

Morales-Martinez, G., \& Lopez-Ramirez, E. (2016). Cognitive responsive e-assessment of constructive e-learning. Journal of e-Learning and Knowledge Society (Je-LKS), 12(4), 39-49.

Morales-Martinez, G., Lopez-Ramirez, E. \& Velasco-Moreno, D. (2016). Alternative elearning assessment by mutual constrain of responsive and constructive techniques of knowledge acquisition evaluation. International Journal for Infonomics (IJI), 9(3), 1195-1200. https://doi.org/10.20533/iji.17 42.4712.2016.0145

Morales-Martinez, G. E., Lopez-Ramirez, E. O. \& Lopez-Gonzalez, A. E. (2016). New approaches to e-cognitive assessment of e-learning. International Journal for eLearning Security (IjeLS), 5(2), 449-453. https://doi.org/10.20533/ijels.2046.4568.2015.0057

Morales-Martinez, G. E., Lopez-Ramirez, E. O., Castro-Campos, C., Villarreal-Treviño, M. G., \& Gonzales-Trujillo, C. J. (2017). Cognitive analysis of meaning and acquired mental representations as an alternative measurement method technique to innovate e-assessment. European Journal of Educational Research, 6(4), 455-464. Retrieved from https://www.eu-jer.com/EU-JER_6_4_455_MoralesMartinez_etal.pdf 
Morales-Martínez, G. E., Lopez-Perez, R. M., Garcia-Collantes, A., \& López-Ramírez, E. O. (2020). Evaluación constructiva cronométrica para evaluar el aprendizaje en línea y presencial [Chronometric constructive assessment to assess online and face-toface learning]. Tecnología, Ciencia y Educación, 15(1), 105-124. Retrieved from https://www.tecnologia-ciencia educacion.com/index.php/TCE/article/view/371

Morales-Martinez, G. E., Lopez-Ramirez, E. O., Garcia-Duran, J. P., \& Urdiales-Ibarra, M. E. (2018). Cognitive constructive-chronometric techniques as a tool for the eassessment of learning. International Journal of Learning, Teaching and Educational Research, 17(2), 159-176. https:/ / doi.org/10.26803/ijlter.17.2.10

Morales-Martinez, G. E., Lopez-Ramirez, E. O., Hedlefs-Aguilar, M. I., \& Gonzáles Trujillo, C. J. (2014). Recuperando el paso en la evaluación del aprendizaje en línea en la era digital: Una aproximación conexionista [Regaining step in online learning assessment in the digital age: A connectionist approach]. Ingenierías, 17(65), 27-37. Retrieved from http://eprints.uanl.mx/10560/1/65_recuperando.pdf

Morales-Martinez, G. E., Mezquita-Hoyos, Y. N., Gonzalez-Trujillo, C. J., Lopez-Ramirez, E. O., \& Garcia-Duran, P. J. (2018). Formative e-assessment of schema acquisition in the human lexicon as a tool in adaptive online instruction. In R. Lopez-Ruiz (Ed.), From natural to artificial intelligence: Algorithms and application (pp. 69-88). IntechOpen. http://doi.org/10.5772/intechopen.81623

Morales-Martinez, G. E., \& Santos-Alcantara, M. G. (2015). Alternative empirical directions to evaluate schemata organization and meaning. Advances in Social Sciences Research Journal, 2(9), 51-58. https://doi.org/10.14738/assrj.29.1412

Pozo, J. I. (2006). Teorías cognitivas del aprendizaje [Cognitive theories of learning] (9th ed.). Morata.

Preston, R., Gratani, M., Owens, K., Roche, P., Zimanyi, M., \& Malau-Aduli, B. (2020). Exploring the impact of assessment on medical students' learning. Assessment $\mathcal{E}$ Evaluation in Higher Education, 45(1), 109-124. http://doi.org/10.1080/02602938.2019.1614145

Rumelhart, D. E., \& Norman, D. A. (1975). The active structural network. In D. A. Norman \& D. E. Rumelhart (Eds.), Explorations in cognition (pp. 35-64). Freeman and Sons.

Rumelhart, D., Smolensky, P., McClelland, J., \& Hinton, G. (1986). Schemata and sequential thought processes in PDP models. In J. McClelland, D. Rumelhart, \& the PDP Research Group (Eds.), Parallel distributed processing: Explorations in the microstructure of cognition: Vol. 2. Psychological and biological models (pp. 7-57). MIT Press.

Samarasekera, D. D., Gopalakrishnakone, P., \& Gwee, M. C. E. (2015). Assessing anatomy as a basic medical science. In L. K. Chan \& W. Pawlina (Eds.), Teaching anatomy: A practical guide (pp. 279-289). Springer. http://doi.org/10.1007/978-3-319-08930-0

Urdiales-Ibarra, M. E., Lopez-Ramirez, E. O., Castro-Campos, C., Villarreal-Treviño, M. G., \& Carrillo-Colon, J. E. (2018). Biology schemata knowledge organization and meaning formation due to learning: A constructive-chronometric approach to concept mapping usability. Creative Education, 9(16), 2992-2706. https://doi.org/10.4236/ce.2018.916203

Vantini, I., \& Benini, L. (2008). Models of learning, training and progress evaluation of medical students. Clinica Chimica Acta, 393(1), 13-16. https://doi.org/10.1016/j.cca.2008.03.015 